\title{
The Lactone Form of Stachybotrydial: A New Inhibitor of Dihydrofolate Reductase from Stachybotrys sp. FN298
}

\author{
Yun-Ju Kwon, Mi-Jin Sohn, Hyun-Ju Kim, and Won-Gon Kim* \\ Superbacteria Research Center, Korea Research Institute of Bioscience and Biotechnology; Yusong, Daejeon \\ 305-806, Korea. \\ Received February 1, 2014; accepted May 11, 2014
}

\begin{abstract}
Dihydrofolate reductase (DHFR) has been confirmed to be a novel target for antibacterial drug development. In this study, we determined that a fungal metabolite from Stachybotrys sp. FN298 can inhibit the DHFR of Staphylococcus aureus. Its structure was identified as a lactone form of stachybotrydial using mass spectrometry and nuclear magnetic resonance analysis. This compound inhibited $S$. aureus DHFR with a half-maximal inhibitory concentration of $41 \mu \mathrm{M}$. It also prevented the growth of $S$. aureus and methicillinresistant $S$. aureus (MRSA) with a minimum inhibitory concentration of $32 \mu \mathrm{g} \cdot \mathrm{mL}^{-1}$. To our knowledge, this is the first description of a DHFR inhibitor of microbial origin. The inhibitory function of the lactone form of stachybotrydial highlights its potential for development into a new broad-spectrum antibacterial agent and as an agent against MRSA.
\end{abstract}

Key words stachybotrydial; dihydrofolate reductase; Staphylococcus aureus; Stachybotrys

Tetrahydrofolate is essential for the survival of both prokaryotic and eukaryotic cells since it is a precursor for the synthesis of purines, some amino acids, and thymidine. Dihydrofolate reductase (DHFR, E.C. 1.5.1.3) catalyzes the transfer of a hydride ion from nicotinamide adenine dinucleotide phosphate (NADPH) to 7,8-dihydrofolate (DHF), forming the product 5,6,7,8-tetrahydrofolic acid. ${ }^{1)}$ Since DHFR is a key enzyme in the biosynthesis of tetrahydrofolate, it has been a target for the treatment of cancer as well as bacterial and parasitic infections. ${ }^{2,3)}$ There are substantial differences between bacterial and mammalian DHFR in terms of amino acid sequence and three-dimensional structures, and the identification of these differences led to the discovery of the antibacterial agent trimethoprim (TMP). ${ }^{3)}$ TMP binds bacterial DHFR with several thousand times higher affinity than that seen for mammalian $\mathrm{DHFR}^{3,4)}$ and is currently in clinical use. In addition, since DHFR is widely conserved in pathogenic bacteria, it is a useful target for the discovery of novel antibacterial agents with a broad spectrum of activity.

TMP, a 5-substituted-2,4-diaminopyrimidine, is a selective inhibitor of bacterial DHFR and has been used as monotherapy or in combination drug therapy for the treatment of urinary tract infections since the mid-1970s. ${ }^{3)}$ TMP exhibits broad-spectrum activity against a wide variety of Gram-positive bacterial pathogens, including Staphylococcus aureus and methicillin-resistant Staphylococcus aureus, and Gram-negative bacteria, including Escherichia coli and Klebsiella pneumoniae. Furthermore, the combination of TMP and isoniazid is bactericidal against Mycobacterium tuberculosis. ${ }^{5)}$ Despite the validation of DHFR as a drug target, TMP remains the only approved antibacterial inhibitor of this enzyme. Many pathogens have now developed TMP-resistant DHFRs, necessitating the discovery of new DHFR inhibitors. ${ }^{6}$ )

Microorganisms produce a variety of antibiotics that function as antagonists in nature to aid in competition. In addition, the targets of many antibiotics have not yet been elucidated.' Although some inhibitors of mammalian DHFR have been isolated from marine resources such as sponges, ${ }^{8)}$ no in-

The authors declare no conflict of interest. hibitors of bacterial DHFR have been isolated from natural resources, with the exception of epigallocatechin-3-gallate. $\left.{ }^{9}\right)$ Thus, the screening of microorganisms for the production of bacterial DHFR inhibitors is warranted.

In this study, we screened for inhibitors of Staphylococcus aureus DHFR from microbial resources. During this process, a rare metabolite containing sesquiterpene and benzofuran was isolated from Stachybotrys sp. FN298, and this inhibitor was identified as a lactone form of stachybotrydial (1) by spectral analysis. Stachybotrydial has been reported as a metabolite of Stachybotrys cylindrospora ${ }^{10)}$ and Stachybotrys sp. F-1839. ${ }^{11)}$ However, the antibacterial activity of stachybotrydial and its lactone form has not been reported previously. In this study, we describe the isolation, Staphylococcus aureus DHFR-specific inhibitory activity, and antibacterial activity of 1 (Fig. 1).

\section{MATERIALS AND METHODS}

General Experimental Methods Nuclear magnetic resonance (NMR) spectra were recorded on the Varian INOVA 400 and Bruker AVANCE II 900 spectrometers (Korea Basic Science Institute, Daejeon, Korea). Electrospray ionization mass spectrometry data were recorded with a Jeol JMSHX110/110 A mass spectrometer. Column chromatography on

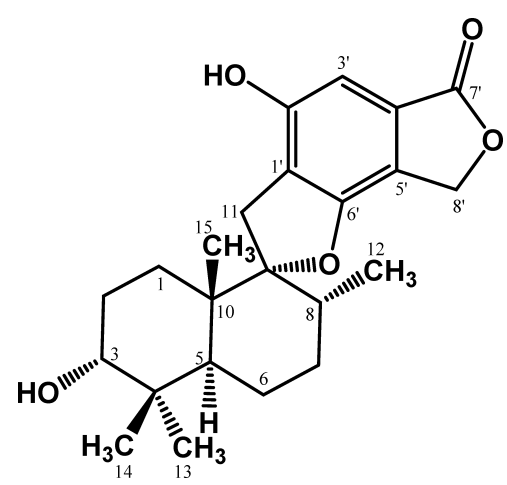

Fig. 1. The Structure of a Lactone Form of Stachybotrydial, Known as Compound 1 
silica gels (Kieselgel 60, 70-230 mesh; Merck, Whitehouse Station, NJ, U.S.A.) and Sephadex LH-20 (GE Healthcare, Pittsburgh, PA, U.S.A.) and thin layer chromatography on precoated $60 \mathrm{~F}_{254}$ silica gels $(0.25 \mathrm{~mm}$; Merck) were conducted. DHF, TMP, vancomycin, norfloxacin, and rifampin were purchased from Sigma-Aldrich (St. Louis, MO, U.S.A.).

Fungal and Bacterial Strains The fungal strain FN298 was isolated from a soil sample collected from a mountain located near Kangnung City, Kangwon-do, Korea. This strain was identified as a Stachybotrys species on the basis of its $18 \mathrm{~S}$ ribosomal RNA (rRNA) sequence. The bacterial strains used in antibacterial assays were acquired from the Culture Collection of Antimicrobial Resistant Microbes of Korea (CCARM) and the Korean Collection for Type Cultures (KCTC).

Fermentation and Compound 1 Isolation Fermentation was conducted in a liquid culture medium containing $0.4 \%$ potato starch and $2 \%$ glucose ( $\mathrm{pH} 5.1$ prior to sterilization). A sample of the FN298 strain from a mature plate culture was inoculated into a $500 \mathrm{~mL}$ Erlenmeyer flask containing $80 \mathrm{~mL}$ of the above sterile seed liquid medium and cultured for $3 \mathrm{~d}$ on a rotary shaker $(150 \mathrm{rpm})$ at $28^{\circ} \mathrm{C}$. For the production of active compounds, $5 \mathrm{~mL}$ of each seed culture was transferred into $500 \mathrm{~mL}$ Erlenmeyer flasks (30 flasks) containing $100 \mathrm{~mL}$ of the same medium, and then cultivated for $7 \mathrm{~d}$ at $28^{\circ} \mathrm{C}$. The fermented whole medium $(2.8 \mathrm{~L})$ was extracted with $100 \%$ acetone and the extract was concentrated in vacuo to an aqueous solution, which was then extracted three times with an equal volume of ethyl acetate. The ethyl acetate extract was dried in vacuo, and then this crude extract was subjected to $\mathrm{SiO}_{2}$ column (Merck) chromatography followed by stepwise elution with $\mathrm{CHCl}_{3}-\mathrm{MeOH}(100: 1,50: 1,10: 1,1: 1)$. The active fractions eluted with $\mathrm{CHCl}_{3}-\mathrm{MeOH}(50: 1)$ were pooled and concentrated in vacuo. The residue $(1.3 \mathrm{~g})$ dissolved in $\mathrm{MeOH}$ was further subjected to Sephadex LH-20 column chromatography and eluted with $\mathrm{CHCl}_{3}-\mathrm{MeOH}(1: 1)$. The active fractions were pooled and concentrated in vacuo. The residue $\left(112 \mathrm{mg}\right.$ ) was subjected to a second round of $\mathrm{SiO}_{2}$ column chromatography followed by elution with $\mathrm{CHCl}_{3}-\mathrm{MeOH}$ $(20: 1)$. The active fraction was finally purified via preparative $\mathrm{SiO}_{2}$ thin layer chromatography developed with $\mathrm{CHCl}_{3}-\mathrm{MeOH}$ $(10: 1)$ to yield $1(16.7 \mathrm{mg})$ at an $R f$ of 0.5 , as a white powder.

Compound 1: $\mathrm{C}_{23} \mathrm{H}_{30} \mathrm{O}_{5}$; a white powder; UV $\lambda_{\max } \mathrm{nm}$ $(\log \varepsilon)$ in MeOH: 220 (4.51), 265 (3.75), 307 (3.50); ${ }^{1} \mathrm{H}-\mathrm{NMR}$ $\left(900 \mathrm{MHz}, \mathrm{CD}_{3} \mathrm{OD}\right) \delta: 6.72\left(1 \mathrm{H}, \mathrm{s}, \mathrm{H}-3^{\prime}\right), 5.34(1 \mathrm{H}, \mathrm{d}$, $\left.J=15.3 \mathrm{~Hz}, \mathrm{H}_{\mathrm{a}}-8^{\prime}\right), 5.19\left(1 \mathrm{H}, \mathrm{d}, J=15.3 \mathrm{~Hz}, \mathrm{H}_{\mathrm{b}}-8^{\prime}\right), 3.33(1 \mathrm{H}, \mathrm{m}$, $\mathrm{H}-3), 3.22\left(1 \mathrm{H}, \mathrm{d}, J=17.1 \mathrm{~Hz}, \mathrm{H}_{\mathrm{a}}-11\right), 2.84(1 \mathrm{H}, \mathrm{d}, J=17.1 \mathrm{~Hz}$, $\left.\mathrm{H}_{\mathrm{b}}-11\right), 2.04(1 \mathrm{H}, \mathrm{dd}, J=13.5,4.5 \mathrm{~Hz}, \mathrm{H}-5), 1.91\left(1 \mathrm{H}, \mathrm{m}, \mathrm{H}_{\beta}-2\right)$, $1.81(1 \mathrm{H}, \mathrm{m}, \mathrm{H}-8), 1.76\left(1 \mathrm{H}, \mathrm{ddd}, J=13.5,13.5,3.6 \mathrm{~Hz}, \mathrm{H}_{\beta}-1\right)$, $1.58\left(1 \mathrm{H}, \mathrm{m}, \mathrm{H}_{\alpha}-7\right), 1.56\left(1 \mathrm{H}, \mathrm{m}, \mathrm{H}_{\alpha}-6\right), 1.50\left(1 \mathrm{H}, \mathrm{m}, \mathrm{H}_{\alpha}-2\right)$, $1.49\left(1 \mathrm{H}, \mathrm{m}, \mathrm{H}_{\beta}-7\right), 1.45\left(1 \mathrm{H}, \mathrm{m}, \mathrm{H}_{\beta}-6\right), 1.05(1 \mathrm{H}, \mathrm{ddd}, J=13.5$, 4.5, 3.6 Hz, $\left.\mathrm{H}_{\alpha}-1\right), 1.01\left(3 \mathrm{H}, \mathrm{s}, \mathrm{H}_{3}-15\right), 0.96\left(3 \mathrm{H}, \mathrm{s}, \mathrm{H}_{3}-13\right)$, $0.86\left(3 \mathrm{H}, \mathrm{s}, \mathrm{H}_{3}-14\right), 0.71\left(3 \mathrm{H}, \mathrm{s}, \mathrm{H}_{3}-12\right) ;{ }^{13} \mathrm{C}-\mathrm{NMR}(125 \mathrm{MHz}$, $\left.\mathrm{CD}_{3} \mathrm{OD}\right) \quad \delta$ : $173.6\left(\mathrm{C}-7^{\prime}\right), 156.3\left(\mathrm{C}-6^{\prime}\right), 155.4\left(\mathrm{C}-2^{\prime}\right), 127.3$ (C-4'), $121.3\left(\mathrm{C}-1^{\prime}\right), 119.2$ (C-5'), 103.1 (C-3'), 99.9 (C-9), 75.8 (C-3), 68.8 (C-8'), 42.9 (C-10), 40.7 (C-5), 38.1 (C-20), 37.8 (C-8), 32.5 (C-11), 31.6 (C-7), 28.6 (C-13), 25.5 (C-2), 24.8 (C-1), 22.8 (C-14), 21.5 (C-6), 16.3 (C-15), 15.8 (C-12); high resolution electrospray ionization mass spectrometry: $\mathrm{m} / \mathrm{z}$ $409.1989[\mathrm{M}+\mathrm{Na}]^{+}, \mathrm{C}_{23} \mathrm{H}_{30} \mathrm{O}_{5} \mathrm{Na}$ requires 409.1985.

Cloning and Inhibition of DHFR The wild-type DHFR gene was amplified by polymerase chain reaction from the genomic DNA of Staphylococcus aureus RN4220. The primers used were 5'-GCT AGCATG ACT TTA TCC ATTCTA GTT GCA-3' and 5'-CTCGAGTTA TTT TTT ACGAAT TAA ATGTAG-3', which contain NdeI and XhoI restriction sites, respectively. After the DNA sequence was confirmed, the DHFR gene was cloned into the pET28a vector (Novagen, Gibbstown, NJ, U.S.A.). This construct was transformed into $E$. coli BL21 (DE3) for expression following induction with isopropyl $\beta$-D-1-thiogalactoside. The N-terminal His-tagged Staphylococcus aureus DHFR was purified using a column of Ni-NTA His-bind Superflow (Novagen) eluted with $200 \mathrm{~mm}$ imidazole. Assays were conducted in half-area, 96-well microtiter plates containing $100 \mu \mathrm{L}$ assay mixture. The Staphylococcus aureus DHFR assay contained $50 \mathrm{~mm}$ potassium phosphate (pH 6.5), $5 \mathrm{~mm} \beta$-mercaptoethanol, $100 \mu \mathrm{M}$ DHF, $100 \mu \mathrm{M}$ NADPH, and $400 \mathrm{~nm}$ Staphylococcus aureus DHFR as previously described. ${ }^{12)}$ The reduction of DHF was spectrophotometrically measured by following the utilization of NADPH at $340 \mathrm{~nm}$ at $30^{\circ} \mathrm{C}$ over the linear period of the assay. The rate of decrease in the amount of NADPH in each reaction well was measured using a microtiter plate reader and the SoftMax Pro software (Molecular Devices, Sunnyvale, CA, U.S.A.). The inhibitory activity was calculated using the following formula: $\%$ inhibition $=100 \times[1-$ (rate in the presence of compound $\div$ rate in the untreated control)]. The half-maximal inhibitory concentration $\left(\mathrm{IC}_{50}\right)$ values were calculated by fitting the data to a sigmoid equation. An equal volume of dimethyl sulfoxide was used for the untreated controls.

Determination of Antibacterial Susceptibility Wholecell antimicrobial activity was determined via broth microdilution, as previously described. ${ }^{13)}$ The test strains were grown to mid-log phase in Mueller-Hinton broth and diluted 1000 -fold in the same medium. Cells $\left(10^{5} / \mathrm{mL}\right)$ were inoculated into Mueller-Hinton broth, with the exception of Streptococcus pneumoniae, which was inoculated into tryptic soy broth containing 5\% sheep blood, and then dispensed at $0.2 \mathrm{~mL} /$ well in 96-well microtiter plates. Minimum inhibitory concentrations (MICs) were determined in triplicate by serially diluting test compounds. The MIC was defined as the concentration of a test compound required to completely inhibit cell growth at $30^{\circ} \mathrm{C}$. Bacterial growth was determined by measuring the absorption at $650 \mathrm{~nm}$ with a microtiter plate reader.

Measurement of the Inhibition of Macromolecular Biosynthesis To monitor the effects of 1 on DNA and RNA biosyntheses, its effects on the incorporation of $\left[2-{ }^{14} \mathrm{C}\right]$ thymidine $\left(59.8 \mathrm{mCi} \cdot \mathrm{mmol}^{-1}\right)$ and $\left[\mathrm{U}^{-14} \mathrm{C}\right]$ uridine $\left(539 \mathrm{mCi} \cdot \mathrm{mmol}^{-1}\right)$ into Staphylococcus aureus were measured as described previously. ${ }^{13)}$ Staphylococcus aureus was exponentially grown to an $\mathrm{A}_{650}$ of 0.2 in Mueller-Hinton broth, and then each 1-mL culture was treated with drugs at two times the MIC for 10 min. An equal volume of dimethyl sulfoxide was added to the untreated control. After incubation with the radiolabeled precursors at $37^{\circ} \mathrm{C}$ for $1 \mathrm{~h}$, followed by centrifugation, the cell pellets were washed twice with phosphate buffered saline (PBS). Incorporation was terminated by adding $10 \%(\mathrm{w} / \mathrm{v})$ trichloroacetic acid and cooling on ice for $20 \mathrm{~min}$. The precipitated material was collected on Whatman GF/C glass microfiber filters, washed with trichloroacetic acid and ethanol, dried, and counted using a scintillation counter. The total counts incorporated during a 1-h incubation without inhibitors ranged from 9000 to 12000 . The inhibition of radiolabeled precursor 
incorporation was calculated using the following formula: \% inhibition $=100 \times[1-$ (radioactivity values of the treated samples/control (no antibacterial) values)]. In all the experiments, known antibacterial agents were included as positive controls.

\section{RESULTS AND DISCUSSION}

Our screening of approximately 5000 microbial extracts (3000 actinomycete and 2000 fungal extracts) using a combination of whole-cell and enzyme assays identified three initial hit strains. Among the initial hits, a metabolite isolated from only one hit strain, Stachybotrys sp. FN298, showed both DHFR-inhibitory activity and antibacterial activity. Compound 1 was isolated via activity-guided fractionation using ethyl acetate extraction, $\mathrm{SiO}_{2}$ column chromatography, Sephadex LH-20 column chromatography, and preparative $\mathrm{SiO}_{2}$ thin layer chromatography from the liquid fermentation broth of the fungal strain FN298. The ${ }^{1} \mathrm{H}$ - and ${ }^{13} \mathrm{C}-\mathrm{NMR}$ data of 1 together with ${ }^{1} \mathrm{H}-{ }^{1} \mathrm{H}$ correlation spectroscopy (COSY), heteronuclear multiple quantum coherence (HMQC), and heteronuclear multiple bond connectivity (HMBC) spectra indicated the presence of 4,6-dioxgenated isobenzofuranone and a drimane-type sesquiterpene. The ${ }^{1} \mathrm{H}$ - and ${ }^{13} \mathrm{C}-\mathrm{NMR}$ data for 1 were almost identical to those of the lactone form of stachybotrydial. ${ }^{11)}$ Based on the nuclear Overhauser effect spectroscopy experiment, the relative stereochemistry of the sesquiterpene moiety was determined to be the same as the reported stereochemistry of stachybotrydial. Thus, its structure was determined to be that of the lactone form of stachy- botrydial (Fig. 1). It has been reported that stachybotrydial spontaneously transforms into its lactone form by the intramolecular Cannizzaro reaction. ${ }^{10,11,14)}$ In the current study, a trace amount of what was believed to be stachybotrydial, based on electrospray ionization mass spectrometry data, was detected at an $R f$ of 0.35 in the final preparative $\mathrm{SiO}_{2}$ thin layer chromatography step involving development with $\mathrm{CHCl}_{3}-\mathrm{MeOH}$ $(10: 1)$. However, the identification of its exact structure and biological activity were not performed due to the compound's limited availability.

Compound 1 inhibited Staphylococcus aureus DHFR in a dose-dependent manner and exhibited an $\mathrm{IC}_{50}$ of $41.5 \mu \mathrm{M}$, while the positive control TMP had an $\mathrm{IC}_{50}$ of $0.25 \mu \mathrm{M}$ (Table 1). Despite its inhibition of DHFR, 1 did not inhibit another reductase, Staphylococcus aureus enoyl-acyl carrier protein (ACP) reductase, even at a concentration of $300 \mu \mathrm{m}$, while the well-known FabI inhibitor triclosan as a positive control had an $\mathrm{IC}_{50}$ of $0.1 \mu \mathrm{M}$ against Staphylococcus aureus enoylACP reductase. TMP also did not inhibit Staphylococcus aureus enoyl-ACP reductase at $10 \mu \mathrm{M}$. These results indicated that inhibition by $\mathbf{1}$ was selective for DFHR like TMP. In order to determine whether $\mathbf{1}$ inhibited cell growth, its antibacterial activity against Gram-positive pathogens, including Staphylococcus aureus, methicillin-resistant Staphylococcus aureus (MRSA), Streptococcus pneumoniae, Bacillus cereus, and Staphylococcus epidermis was evaluated. Compound $\mathbf{1}$ exhibited antibacterial activity against Staphylococcus aureus RN4220, MRSA CCARM 3167 and CCARM 3506, Streptococcus pneumoniae KCTC 5412, B. cereus KCTC 1661,

Table 1. The Inhibitory Activity of Compound 1 against Staphylococcus aureus DHFR, Bacterial Viability, and DNA and RNA Biosyntheses in Staphylococcus aureus

\begin{tabular}{|c|c|c|c|c|c|}
\hline & \multirow{2}{*}{$\begin{array}{l}\mathrm{IC}_{50}(\mu \mathrm{M}) \\
s a \mathrm{DHFR}^{a)}\end{array}$} & \multicolumn{2}{|c|}{$\operatorname{MIC}\left(\mu \mathrm{g} \cdot \mathrm{mL}^{-1}\right)$} & \multicolumn{2}{|c|}{$\begin{array}{c}\text { Inhibition of precursor incorporation } \\
\text { at } 2 \times \mathrm{MIC}(\%)\end{array}$} \\
\hline & & Staphylococcus aureus ${ }^{b)}$ & $\mathrm{MRSA}^{c)}$ & {$\left[2-{ }^{14} \mathrm{C}\right]$ Thymidine } & {$\left[\mathrm{U}-{ }^{14} \mathrm{C}\right]$ Uridine } \\
\hline 1 & 41.5 & 32 & 32 & 68 & 79 \\
\hline Reference compounds ${ }^{d)}$ & 0.25 & 1 & 1 & 73 & 72 \\
\hline
\end{tabular}

a) Staphylococcus aureus DHFR, b) Staphylococcus aureus RN4220, c) Methicillin-resistant Staphylococcus aureus CCARM3167, d) Reference compounds used for $s a$ DHFR inhibition, cell viability, thymidine, and uridine incorporation are TMP, vancomycin, norfloxacin, and rifampin, respectively.
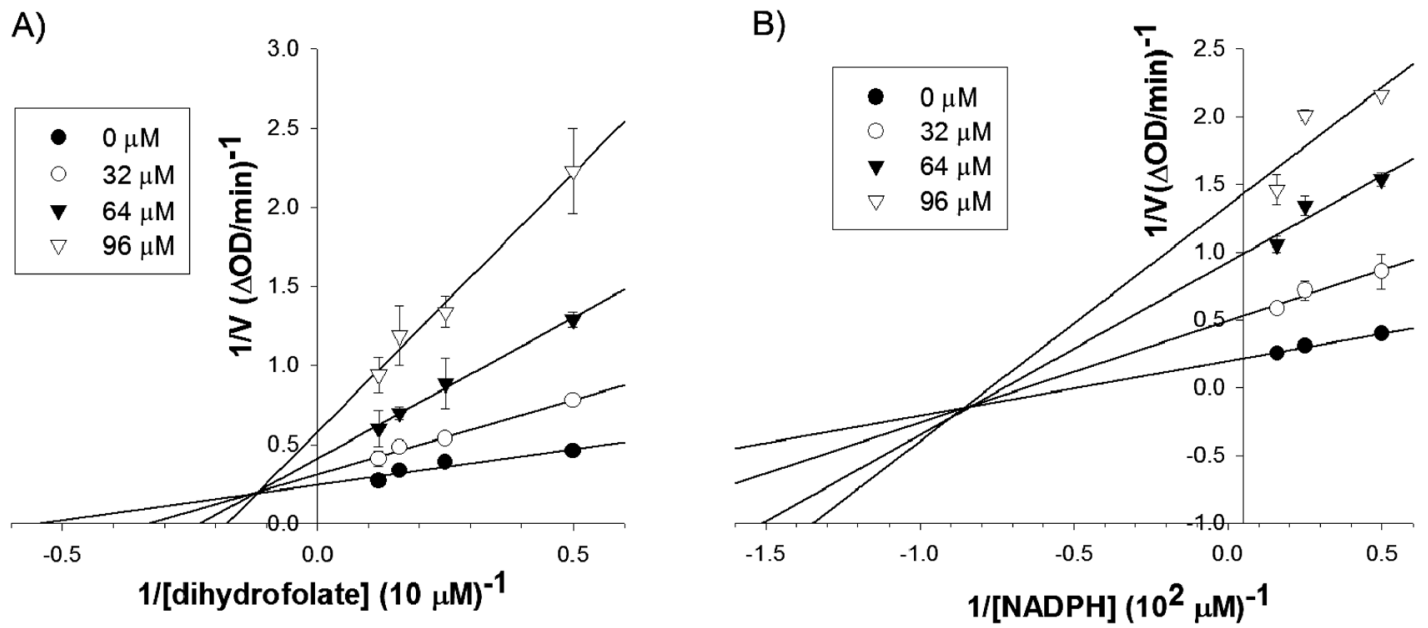

Fig. 2. The Mechanism of Inhibition of Staphylococcus aureus DHFR by Compound $\mathbf{1}$

The reciprocals of the initial reaction, (A) substrate (DHF), and (B) cofactor (NADPH) concentrations are plotted. The values are expressed as the mean \pm S.D. from triplicate measurements in two independent experiments. 
and Staphylococcus epidermis KCTC 3958 with MICs of 32-64 $\mu \mathrm{g} \cdot \mathrm{mL}^{-1}$. However, 1 did not show antibacterial activity against Gram-negative bacteria such as E. coli CCARM 1356 and Pseudomonas aeruginosa KCTC 2004 at $128 \mu \mathrm{g} \cdot \mathrm{mL}^{-1}$. As a positive control, vancomycin showed MICs of $1-2 \mu \mathrm{g} \cdot \mathrm{mL}^{-1}$ against these Gram-positive strains. These data suggest a correlation between the enzyme-inhibitory and antibacterial activities of $\mathbf{1}$.

In the Lineweaver-Burk plot analysis (Fig. 2), 1 showed mixed-type inhibition of Staphylococcus aureus DHFR with respect to the substrate DHR, with a $K_{\mathrm{i}}$ value of $7.4 \mu \mathrm{M}$. Similarly, 1 showed a mixed-type inhibitory effect against Staphylococcus aureus DHFR with respect to the cofactor NADPH, with a $K_{\mathrm{i}}$ value of $23.9 \mu \mathrm{M}$. These results indicate that 1 binds to both the free enzyme and the enzyme-substrate complex.

In order to determine whether the antibacterial effect of 1 was attributable to the inhibition of DNA and RNA syntheses, we attempted to ascertain whether this compound blocked the in vivo incorporation of thymidine and uridine into DNA and RNA, respectively. We measured the effect of $\mathbf{1}$ on the incorporation of $\left[2-{ }^{14} \mathrm{C}\right]$ thymidine and $\left[\mathrm{U}-{ }^{14} \mathrm{C}\right]$ uridine into DNA and RNA, respectively, in $S$. aureus. When compared with untreated cells, 1 was found to inhibit DNA and RNA syntheses in vivo by $68 \%$ and $79 \%$, respectively, at two times the MIC (Table 1). Norfloxacin and rifampin were used as positive controls and these antibacterial agents inhibited thymidine and uridine incorporation by $73 \%$ and $72 \%$, respectively.

Stachybotrydial has been previously identified as a cholesterol esterase inhibitor and an avian myeloblastosis virus protease inhibitor from Stachybotrys sp. F-1839 ${ }^{10)}$ and Stachybotrys sp. Mer-NF5003, ${ }^{15)}$ respectively. It was also reported to exhibit antiviral and antiplasmodial activities ${ }^{14)}$ and enhance the fibrin binding of Glu-plasminogen. ${ }^{16)}$ However, the antibacterial activity of stachybotrydial and its lactone form has not been reported previously.

Sulfonamides and diaminopyrimidine are classical scaffolds of bacterial DHFR inhibitors. Various synthetic analogs of diaminopyrimidine, including iclaprim, have been developed via three-dimensional structure-based rational design ${ }^{3,17)}$ Iclaprim is a promising antibacterial drug, which is currently being tested in a Phase III clinical trial. Recently, the discovery of new scaffolds for nonclassical DHFR inhibitors, including thiazoles, ${ }^{18)}$ quinolinones,${ }^{19)}$ and propargyl-linked compounds ${ }^{20,21)}$ have been reported. Cytotoxic puupehenone (sesquiterpene hydroquinone) and bastadin from the Verongid sponges were reported to inhibit mammalian DHFR. ${ }^{22,23)}$ In addition, a component of green tea known as EGCG was reported to inhibit both mammalian and bacterial DHFR., ${ }^{94,25)}$ However, we believe that this is the first report of a bacterial DHFR inhibitor of microbial origin, namely, the lactone form of stachybotrydial.

In conclusion, the lactone form of stachybotrydial inhibited Staphylococcus aureus DHFR and also exhibited antibacterial activity against Staphylococcus aureus and MRSA. It also exhibited inhibition of DNA and RNA biosyntheses in Staphylococcus aureus, which is consistent with its Staphylococcus aureus DHFR inhibitory activity. In this study, we have reported the inhibitory effects of the lactone form of stachybotrydial on Staphylococcus aureus DHFR and its impact on bacterial viability. This compound may provide to be a useful chemical scaffold for the development of a novel broad-spectrum anti- bacterial that can also function as an anti-MRSA agent.

Acknowledgments This work was supported by the Basic Science Research Program through the National Research Foundation of Korea (NRF) funded by the Ministry of Education, Science and Technology (2012R1A2A2A01014821), KRIBB Research Initiative Program, and the Intelligent Synthetic Biology Center of Global Frontier Project (20110031944), Republic of Korea.

\section{REFERENCES}

1) Kompis IM, Islam K, Then RL. DNA and RNA synthesis: antifolates. Chem. Rev., 105, 593-620 (2005).

2) Then RL. Antimicrobial dihydrofolate reductase inhibitors-achievements and future options. J. Chemother., 16, 3-12 (2004), review.

3) Hawser S, Lociuro S, Islam K. Dihydrofolate reductase inhibitors as antibacterial agents. Biochem. Pharmacol., 71, 941-948 (2006).

4) Hitchings GH, Burchall JJ. Inhibition of folate biosynthesis and function as a basis for chemotherapy. Adv. Enzymol. Relat. Areas Mol. Biol., 27, 417-468 (1965).

5) Vilchèze C, Jacobs WR Jr. The combination of sulfamethoxazole, trimethoprim, and isoniazid or rifampin is bactericidal and prevents the emergence of drug resistance in Mycobacterium tuberculosis. Antimicrob. Agents Chemother, 56, 5142-5148 (2012).

6) Huovinen P. Resistance to trimethoprim-sulfamethoxazole. Clin. Infect. Dis., 32, 1608-1614 (2001).

7) Singh MP, Greenstein M. Antibacterial leads from microbial natural products discovery. Curr. Opin. Drug Discov. Devel., 3, 167-176 (2000).

8) Nakao Y, Fusetani N. Enzyme inhibitors from marine invertebrates. J. Nat. Prod., 70, 689-710 (2007).

9) Spina M, Cuccioloni M, Mozzicafreddo M, Montecchia F, Pucciarelli S, Eleuteri AM, Fioretti E, Angeletti M. Mechanism of inhibition of wt-dihydrofolate reductase from $E$. coli by tea epigallocatechin-gallate. Proteins, 72, 240-251 (2008).

10) Ayer WA, Miao S. Secondary metabolites of the aspen fungus Stachybotrys cylindrospora. Can. J. Chem., 71, 487-493 (1993).

11) Sakai K, Watanabe K, Masuda K, Tsuji M, Hasumi K, Endo A. Isolation, characterization and biological activities of novel triprenyl phenols as pancreatic cholesterol esterase inhibitors produced by Stachybotrys sp. F-1839. J. Antibiot., 48, 447-456 (1995).

12) Baccanari DP, Joyner SS. Dihydrofolate reductase hysteresis and its effect of inhibitor binding analyses. Biochemistry, 20, 1710-1716 (1981).

13) Zheng CJ, Sohn MJ, Lee S, Kim WG. Meleagrin, a new FabI inhibitor from penicillium chryosogenum with at least one additional mode of action. PLoS ONE, 8, e78922 (2013).

14) Sawadjoon S, Kittakoop P, Isaka M, Kirtikara K, Madla S, Thebtaranonth Y. Antiviral and antiplasmodial spirodihydrobenzofuran terpenes from the fungus Stachybotrys nephrospora. Planta Med., 70, 1085-1087 (2004).

15) Kaneto R, Dobashi K, Kojima I, Sakai K, Shibamoto N, Yoshioka T, Nishida H, Okamoto R, Akagawa H, Mizuno S. Mer-NF5003B, E and $\mathrm{F}$, novel sesquiterpenoids as avian myeloblastosis virus protease inhibitors produced by Stachybotrys sp. J. Antibiot., 47, 727-730 (1994).

16) Sasaoka M, Wada Y, Hasumi K. Stachybotrydial selectively enhances fibrin binding and activation of Glu-plasminogen. J. Antibiot., 60, 674-681 (2007).

17) Schneider P, Hawser S, Islam K. Iclaprim, a novel diaminopyrimidine with potent activity on trimethoprim sensitive and resistant bacteria. Bioorg. Med. Chem. Lett., 13, 4217-4221 (2003).

18) Hassan GS, El-Messery SM, Al-Omary FA, Al-Rashood ST, Shabayek MI, Abulfadl YS, Habib el-SE, El-Hallouty SM, Fayad W, 
Mohamed KM, El-Menshawi BS, El-Subbagh HI. Nonclassical antifolates, part 4. 5-(2-Aminothiazol-4-yl)-4-phenyl-4H-1,2,4-triazole3-thiols as a new class of DHFR inhibitors: synthesis, biological evaluation and molecular modeling study. Eur. J. Med. Chem., 66 , 135-145 (2013)

19) Zolli-Juran M, Cechetto JD, Hartlen R, Daigle DM, Brown ED. High throughput screening identifies novel inhibitors of Escherichia coli dihydrofolate reductase that are competitive with dihydrofolate. Bioorg. Med. Chem. Lett., 13, 2493-2496 (2003).

20) Viswanathan K, Frey KM, Scocchera EW, Martin BD, Swain PW III, Alverson JB, Priestley ND, Anderson AC, Wright DL. Toward new therapeutics for skin and soft tissue infections: propargyllinked antifolates are potent inhibitors of MRSA and Streptococcus pyogenes. PLoS ONE, 7, e29434 (2012).

21) Frey KM, Viswanathan K, Wright DL, Anderson AC. Prospective screening of novel antibacterial inhibitors of dihydrofolate reduc- tase for mutational resistance. Antimicrob. Agents Chemother., 56, 3556-3562 (2012).

22) Hamman MT, Scheuer PJ, Kelly-Borges M. Biogenetically diverse, bioactive constituents of a sponge, order Verongida: Bromotyramines and sesquiterpene-Shikimate derived metabolites. $J$. Org. Chem., 58, 6565-6569 (1993).

23) Carney JR, Scheuer PJ, Kelly-Borges M. A new bastadin from the sponge Psammaplysilla purpurea. J. Nat. Prod., 56, 153-157 (1993).

24) Lucock MD, Roach PD. The antifolate activity of tea catechins. Cancer Res., 65, 8573 (2005).

25) Navarro-Perán E, Cabezas-Herrera J, Hiner ANP, Sadunishvili T, García-Cánovas F, Rodríguez-López JN. Kinetics of the inhibition of bovine liver dihydrofolate reductase by tea catechins: Origin of slow-binding inhibition and $\mathrm{pH}$ studies. Biochemistry, 44, 75127525 (2005). 